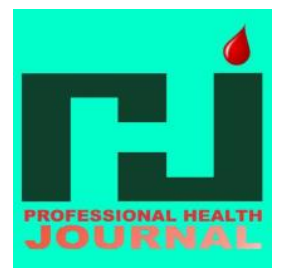

PROFESIONAL HEALTH JOURNAL

Volume2, No. 2, Juni 2021 (Hal. 90-100)

https://www.ojsstikesbanyuwangi.com/index.php/PHJ

\title{
Hubungan Antara Peran Orangtua dengan Teknik Menggosok Gigi yang Baik dan Benar pada Anak Pra Sekolah Usia 4-6 Tahun
}

\author{
Novi Setia Prasiska ${ }^{\text {a }}$ Lilla Maria ${ }^{a}$, Previta Zeisar Rahmawati ${ }^{a}$ \\ ${ }^{a}$ Ilmu Keperawatan Stikes Maharani Malang
}

Email Korespondensi: Novisetia@gmail.com

\begin{abstract}
Introduction:The role of parents is a form of behavior shown by parents to develop a child's personality. In preschool children, in maintaining dental health is still dependent on parents. The role of parents is very influential in teaching children how to brush their teeth properly and correctly so that children can maintain healthy teeth. The purpose of this study was to determine correlation between the role of parents and the proper and correct technique of teeth brushing in preschool children aged 4-6 years in PAUD Dewi Sartika, Dinoyo Village, Lowok Waru District, Malang City. Methode: The design of this study was descriptive correlational with cross sectional approach. The number of respondents were forty two people who were selected by using total sampling techniques. The research used questionnaire for the parent role and observation sheet for the technique of teeth brushing in preschoolers. Result This study used Spearman statistical test with significance level $(\alpha)=0.05$. The results showed that there was correlation between the role of parents and the proper and correct technique of teeth brushing in preschoolers aged 4-6 years in PAUD Dewi Sartika, Dinoyo Village, Lowok Waru District, Malang City. The results of the analysis showed $p$ value: $0,000<\alpha: 0,05$; the value $(r)=0,628$ with significant value of 0,000. Conclucion Based on the results of the study, it recommends parents to improve their role in guiding and supervising children in brushing their teeth.
\end{abstract}

Keywords: Role of Parents, Teeth Brushing Technique, Preschool Children.

\begin{abstract}
ABSTRAK
Pendahuluan: Peran orang tua merupakan bentuk perilaku yang ditunjukkan oleh orang tua untuk mengembangkan kepribadian anak. Pada anak prasekolah, dalam menjaga kesehatan gigi masih bergantung pada orang tua. Peran orang tua sangat berpengaruh dalam mengajarkan anak cara menggosok gigi dengan baik dan benar agar anak dapat menjaga kesehatan giginya. Tujuan penelitian ini adalah untuk mengetahui hubungan peran orang tua dengan teknik menggosok gigi yang baik dan benar pada anak usia prasekolah usia 4-6 tahun di PAUD Dewi Sartika Desa Dinoyo Kecamatan Lowok Waru Kota Malang. Metode: Desain penelitian ini adalah deskriptif korelasional dengan pendekatan cross sectional. Jumlah responden sebanyak empat puluh dua orang yang dipilih dengan menggunakan teknik total sampling. Penelitian ini menggunakan kuesioner peran orang tua dan lembar observasi teknik menyikat gigi pada anak prasekolah. Penelitian ini menggunakan uji statistik Spearman dengan taraf signifikansi $(\alpha)=0,05$. Hasil: penelitian menunjukkan bahwa ada hubungan antara peran orang tua dengan teknik menggosok gigi yang benar dan benar pada anak usia prasekolah usia 4-6 tahun di PAUD Dewi Sartika Desa Dinoyo, Kecamatan Lowok Waru, Kota Malang. Hasil analisis menunjukkan p value : 0,000<
\end{abstract}




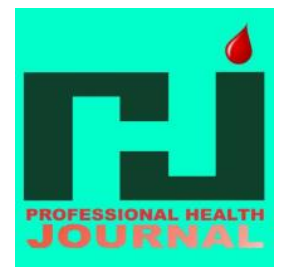

PROFESIONAL HEALTH JOURNAL

Volume2, No. 2, Juni 2021 (Hal. 90-100)

https://www.ojsstikesbanyuwangi.com/index.php/PHJ

: 0,05 ; nilai $(r)=0,628$ dengan nilai signifikansi 0,000 . Kesimpulan: Berdasarkan hasil penelitian, disarankan kepada orang tua untuk meningkatkan perannya dalam membimbing dan mengawasi anak dalam menggosok gigi.

Kata kunci: Peran Orang Tua, Teknik Menggosok Gigi, Anak Prasekolah.

\section{PENDAHULUAN}

Orangtua adalah komponen keluarga yang terdiri dari ayah dan ibu, dan merupakan hasil dari sebuah ikatan perkawinan yang sah yang dapat membentuk sebuah keluarga. Orangtua memiliki tanggung jawab untuk mendidik, mengasuh dan membimbing anak-anaknya untuk mencapai tahapan tertentu yang menghantarkan anak untuk siap dalam kehidupan bermasyarakat (Arif, 2010).

Dalam keluarga orangtua memiliki peran penting dalam meningkatkan kesehatan anak yang meliputi makan dengan menu seimbang, olah raga teratur, istirahat cukup, kebersihan diri, mencuci kaki sebelum tidur atau mencuci tangan sebelum makan dan menggosok gigi sebelum tidur (Notoatmodjo, 2007).

Peran orangtua dalam membimbing, memberikan perhatian, memberikan pengertian, mengingatkan dan menyediakan fasilitas kepada anak agar anak dapat memelihara kebersihan giginya. Peran orangtua terhadap bagaimana menjaga kesehatan gigi sangat penting dalam mendasari terbentuknya perilaku yang mendukung kebersihan gigi anak sehingga kesehatan gigi anak dapat terjaga dengan baik (Gultom, 2009).

Sikap dan perilaku orang tua dalam pemeliharaan kesehatan gigi pada anak memberi pengaruh yang cukup signifikan terhadap perilaku anak. Orangtua dapat mengurangi risiko terjadinya kerusakan gigi dengan melakukan pencegahan dengan cara berkumur dengan air bersih setelah minum susu maupun makan makanan manis, membiasakan anaknya memeriksakan gigi mereka ke dokter gigi 2 kali dalam 1 tahun dan menggosok gigi untuk menjaga kebersihan gigi dan mulut (Suciari dkk., 2015).

Kesehatan mulut merupakan hal penting untuk kesehatan secara umum dan kualitas hidup. Kesehatan mulut berarti terbebas dari kanker tenggorokan, infeksi dan luka pada mulut, penyakit gusi, kerusakan gigi, kehilangan gigi, dan penyakit lainnya, sehingga terjadi gangguan yang membatasi dalam menggigit, mengunyah, tersenyum, berbicara, dan kesejahteraan psikososial (WHO, 2012).

Gigi bagi seorang anak penting dalam proses pertumbuhan dan perkembangan anak itu sendiri (Amin et al., 2018). Fungsi gigi sangat diperlukan dalam masa anak-anak yaitu sebagai alat pengunyah, membantu dalam berbicara, keseimbangan wajah, penunjang estetika wajah anak dan khususnya gigi sulung berguna sebagai panduan pertumbuhan gigi permanen. Anak usia prasekolah adalah anak yang berusia antara 2 sampai 6 tahun dimana pada masa ini anak telah mencapai kematangan dalam berbagai macam fungsi motorik dan diikuti dengan perkembangan intelektual dan sosioemosional. (RISKESDAS, 2013).

Pada anak usia prasekolah, pemeliharaan kesehatan gigi mereka masih bergantung kepada orangtua. Mulai tumbuhnya gigi merupakan proses penting dari pertumbuhan seorang anak. Orangtua harus mengetahui cara merawat gigi 
anaknya tersebut dan juga harus membimbing anaknya cara menyikat gigi yang baik dan benar. Walaupun masih memiliki gigi susu, seorang anak harus mendapatkan perhatian yang serius dari orangtuanya karena gigi susu akan mempengaruhi pertumbuhan gigi permanen anak. Akan tetapi banyak orangtua yang beranggapan bahwa gigi susu hanya sementara dan akan diganti oleh gigi permanen sehingga mereka sering menganggap bahwa kerusakan pada gigi susu yang disebabkan oleh oral hygiene yang buruk bukan merupakan suatu masalah (Gultom, 2009).

Laporan hasil Riset Kesehatan Dasar (RISKESDAS) tahun 2013 menyebutkan bahwa masalah kesehatan gigi dan mulut mencapai presentase sebesar $25,9 \%$ dan sebanyak 14 provinsi prevalensinya melebihi angka nasional tersebut. Sulawesi Utara pada tahun 2013 memiliki angka presentase penduduk yang memiliki masalah gigi dan mulut sebanyak $31,6 \%$, yang menerima perawatan dari tenaga medis gigi jauh lebih rendah yaitu $25 \%$. Hal lain yang menjadi perhatian yaitu proporsi penduduk memiliki masalah gigi dan mulut pada kelompok anak usia 1-4 tahun sebesar $10,4 \%$ dan anak usia 5-9 tahun sebesar $28,9 \%$ dengan persentase tertinggi sebesar $30,5 \%$ pada usia $35-44$ tahun.Hal ini menunjukan persentase masalah gigi dan mulut pada usia 5-9 tahun sudah memasuki angka yang cukup tinggi.

Penelitian yang dilakukan oleh peneliti Taverud (2009) menunjukkan bahwa prevalensi karies gigi pada anak sangat bervariasi jika didasarkan atas golongan umur dimana anak berusia 1 tahun sebesar 5\%, anak usia 2 tahun sebesar $10 \%$, anak usia 3 tahun sebesar $40 \%$, anak usia 4 tahun sebesar 55\%, dananak usia 5 tahun sebesar $75 \%$. Dengan demikian golongan umur balita merupakan golongan rawan terjadinya karies gigi.

Hasil penelitian Suryawati,dkk (2009) menyebutkan bahwa 76,8\% ibu dengan anak balita memiliki peran yang kurang terhadap kesehatan gigi dan mulut anaknya dan $71,33 \%$ ibu tidak pernah memeriksakan gigi anak balitanya ke dokter gigi karena mereka beranggapan bahwa gigi susu hanya sementara dan akan diganti dengan gigi permanen sehingga ibu menganggap kerusakan pada gigi susu bukan merupakan suatu masalah (Suryawati,dkk. 2009).

Penelitian yang dilakukan oleh Susi tahun 2011 di beberapa taman kanak-kanak di Padang menunjukan anak yang memiliki ibu yang berpendidikan sarjana memiliki status karies baik sebesar 53,3\%, dan anak yang memiliki ibu yang tidak sarjana, mempunyai status karies buruk lebih tinggi yaitu 58,3\%. Sedangkan menurut Solikin tahun 2013 di Karanganyar, menunjukan bahwa, pengetahuan ibu dengan kategori kurang baik anaknya mengalami karies gigi sebesar 97,6\% sedangkan tingkat pengetahuan ibu dengan kategori baik anaknya yang mengalami karies sebanyak $12,5 \%$.

Pada anak usia prasekolah, pemeliharaan kesehatan gigi mereka masih bergantung kepada orang tua sebagai orangterdekat anak. Mulai tumbuhnya gigi merupakan proses penting dari pertumbuhan seorang anak. Orangtua khususnya ibu harus mengetahui cara merawat gigi anaknya. Peran orangtua sangat berpengaruh dalam merawat dan memelihara kesehatan gigi anak secara teratur seperti menyikat gigi, memperhatikan pola makan dan melakukan pemeriksaan secara rutin keklinik gigi (Suherman, 2010). 


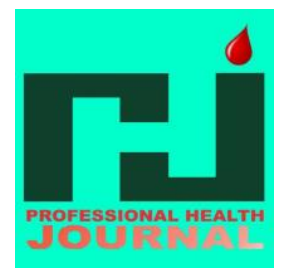

Berdasarkan studi pendahuluan yang dilakukan oleh peneliti dengan wawancara langsung pada salah satu guru bahwa peserta didik di PAUD Dewi Sartika Kelurahan Dinoyo yang berjumlah 110 anak, tetapi yang aktif hadir hanya 70-80 anak. Peneliti mengajarkan cara menggosok gigi yang benar pada anak kemudian anak memperaktikkan ulang apa yang diajarkan oleh peneliti sedangkan peneliti mengobservasi cara menggosok gigi yang benar pada anak sesuai dengan yang diajarkan oleh peneliti. Dari 10 anakdidapatkanhasilyaitu 4 anak yang menggosok gigi dengan benar sedangkan 6 anak masih belum mampu menggosok gigi dengan benar.Selain itu didapatkan dari 10 orang ibu, ada 4 orang ibu yang selalu mengajarkan dan menemani anaknya menggosok gigi setiap pagi dan malam hari sebelum tidur, ada 3 orang ibu yang menyuruh anaknya menggosok gigi tanpa mengawasi anaknya, ada 3 orang ibu yang jarang menyuruh atau mengawasi anaknya menggosok gigi.

Berdasarkan latar belakang diatas maka peneliti tertarik untuk melakukan penelitian tentang hubungan antara peran orang tua dengan teknik menggosok gigi yang baik dan benar pada anak pra sekolah usia 4-5 tahun di PAUD Dewi Sartika Kelurahan Dinoyo Kecamatan Lowok Waru Kota Malang

\section{BAHAN DAN METODE}

Pada rancangan penelitian ini menggunakan rancangan deskriptif korelasional dengan pendekatan cross sectional, karena menghubungkan 2 variabel peran orangtua dengan teknik menggosok gigi yang baik dan benar pada anak usia prasekolah. Populasi dalam penelitian ini sebanyak 42 orang. Pada penelitian ini menggunakan pengambilan
PROFESIONAL HEALTH JOURNAL

Volume2, No. 2, Juni 2021 (Hal. 90-100)

https://www.ojsstikesbanyuwangi.com/index.php/PHJ

teknik total sampling yaitu pada penelitian ini sampel (responden) yang diambil yaitu adalah orangtua dan siswa yang berusia 4-6 tahun yaitu sebanyak 42 siswa yang terdapat di PAUD Dewi Sartika Kelurahan Dinoyo Kecamatan Lowokwaru Kota Malang. No ec pada penelitian ini adalah Reg.No.:/481/KEPK-POLKESMA/2018

Variabel dependent pada penelitian ini peran orangtua dan variabel independent teknik menggosok gigi yang baik dan benar pada anak usia prasekolah dengan menggunakan kuesioner dan lembar observasi. Analisis data untuk mengetahui adanya hubungan antara peran orangtua dengan teknik menggosok gigi yang baik dan benar pada anak pra sekolah uji statistik yaitu Uji Spearman dengan signifikasi $(\mathrm{p}=$ $0,05)$

\section{HASIL}

Tabel 5.5 Distribusi frekuensi terhadap peran orang tua dalam membimbing anak

\begin{tabular}{|c|c|c|c|}
\hline No & $\begin{array}{c}\text { Peran Orang } \\
\text { Tua }\end{array}$ & Jumlah & $\begin{array}{c}\text { Persentase } \\
(\%)\end{array}$ \\
\hline 1 & Baik & 21 & 50 \\
\hline 2 & Cukup & 12 & 28,57 \\
\hline 3 & Kurang & 9 & 21,42 \\
\hline \multicolumn{2}{|c|}{ Jumlah } & 42 & 100 \\
\hline
\end{tabular}

Berdasarkan tabel 5.5 dapat diketahui bahwa dari 42 responden setengah responden tergolong dalam kategori dalam membimbing anak menggosok gigi yang baik yaitu 21 responden $(50 \%)$. 
PROFESIONAL HEALTH JOURNAL

Volume2, No. 2, Juni 2021 (Hal. 90-100)

https://www.ojsstikesbanyuwangi.com/index.php/PHJ

Tabel 5.6 Distribusi frekuensi terhadap teknik menggosok gigi anak usia pra sekolah

\begin{tabular}{|c|c|c|c|}
\hline No & $\begin{array}{c}\text { Teknik } \\
\text { Menggosok Gigi }\end{array}$ & jumlah & $\begin{array}{c}\text { Persentase } \\
(\%)\end{array}$ \\
\hline 1 & Baik & 18 & 42,85 \\
\hline 2 & Cukup & 16 & 38,09 \\
\hline 3 & Kurang & 8 & 19,04 \\
\hline \multicolumn{2}{|c|}{ Total } & 42 & 100 \\
\hline
\end{tabular}

Berdasarkan tabel 5.6 bahwa dari 42 anak usia pra sekolah hampir setengah termasuk kedalam dalam teknik menggosok gigi yang baik yaitu 18 anak (42\%).

Tabel 5.8 Peran Orangtua dengan Teknik Menggosok Gigi yang Baik dan Benar pada Anak Pra Sekolah

Dari Uji Spearman rho Berdasarkan tabel 5.8 hasil pengujian hubungan antara peran orangtua dengan teknik menggosok gigi yang baik dan benar pada anak pra sekolah didapatkan nilai signifikansi sebesar 0,000 . Nilai signifikansi lebih kecil dari $a=0,05$, menunjukan adanya hubungan antara peran oarngtua dengan teknik meggosok gigi yang baik dan benar pada anak usia pra sekolah. Nilai korelasi Spearman hasil perhitungan yaitu $(\mathrm{r})=0,628$ artinya kekuatan yang terbentuk berada pada kategori kuat. Dengan arah hubungan (r) positif artinya semakin baik peran orangtua maka teknik menggosok yang baik dan benar pada anak usia pra sekolah semakin baik.

\section{PEMBAHASAN}

Peran Orangtua

$\begin{array}{lll}\text { Teknik } & \mathrm{r} & 0.628 \\ \text { Menggosok } & \alpha & 0,000 \\ \text { Gigi } & \mathrm{n} & 42\end{array}$

Peran Orang Tua pada Anak Usia Prasekolah di PAUD Dewi Sartika Kelurahan Dinoyo Kecamatan Lowokwaru Kota Malang

Berdasarkan hasil penelitian dari 42 responden didapatkan bahwa setengan dari responden tegolong dalam katagori peran orangtua yang baik yaitu 21 responden (50\%), hampir setengahnya tergolong dalam kategori peran orang tua yang cukup yaitu 12 responden $(28,57 \%)$, dan sebagian kecil tergolong dalam kategori peran orang tua yang kurang yaitu 9 responden $(21,42 \%)$. Peran orangtua adalah tingkah laku ayah dan ibu dalam bekerjasama dan bertanggung jawab terhadap keturunannya, terhadap bentuk tubuh maupun sikap moral, spiritual maupun emosional anak yang mandiri (Pratiwi, 2010).

Peran orangtua terutama seorang ibu terhadap bagaimana menjaga kesehatan gigi sangat penting dalam mendasari terbentuknya perilaku yang mendukung kebersihan gigi anak sehingga kesehatan gigi anak dapat terjaga dengan baik. Kesehatan gigi susu sangat mempengaruhi perkembangan dan pertumbuhan gigi permanen, oleh karena itu peran serta orangtua sangat diperlukan di dalam membimbing, memberikan perhatian, memberikan pengertian, mengingatkan dan menyediakan fasilitas kepada anak agar anak kelak dapat memelihara kebersihan giginya (Gultom, 2009).

Menurut pendapat peneliti berdasarkan kuesioner yang telah peneliti bagikan kepada orangtua responden terdapat peran orangtua yang sering dilakukan adalah mengajarkan anak menggosok gigi dan dan memberitahukan kepada anak waktu-waktu menyikat gigi dalam sehari. Berdasarkan tabel 5.3 
PROFESIONAL HEALTH JOURNAL

Volume2, No. 2, Juni 2021 (Hal. 90-100)

https://www.ojsstikesbanyuwangi.com/index.php/PHJ

karakteristik pendidikan ibu didapatkan hasil bahwa pendidikan ibu dari 42 responden sebagian besar belatar belakang SMA yaitu 21 responden (50\%). Penelitian ini sejalan dengan teori Mubarak (2009), yang mengatakan bahwa pendidikan berarti bimbingan yang diberikan seseorang pada orang lain terhadap sesuatu hal agar mereka dapat memahami. Tidak dapat dipungkiri bahwa makin tinggi pendidikan seseorang semakin mudah pula mereka menerima informasi, dan pada akhirnya makin banyak pula pengetahuan yang dimilikinya. Sebaliknya jika seseorang tingkat pendidikannya rendah, akan menghambat perkembangan sikap dan pengetahuan seseorang terhadap penerimaan informasi dan nilai-nilai yang baru diperkenalkan. Menurut teori Nursalam (2011) yang menyatakan bahwa pendidikan sangat berperan dalam membina sikap, pandangan dan kemampuan, disini orang tua mempunyai pendidikan yang tinggi akan dapat memberikan arah yang baik terhadap anak daripada oran tua yang mempunyai pendidikan rendah.

Pekerjaan juga berpengaruh pada peran orang tua. Pada tabel 5.4 karakteristik pekerjaan ibu didapatkan bahwa dari 42 responden sebagian besar pekerjaan orang tua adalah ibu rumah tangga (IRT) yaitu sebanyak 21 responden (50\%). Dari hasil penelitian ini didapatkan bahwa pekerjaan yang terbanyak orang tua adalah sebagai ibu rumah tangga. Menurut Nursalam (2011), pekerjaan adalah kebutuhan yang harus dilakukan untuk menunjang kehidupannya dan kehidupan keluarganya. Bekerja pada umumnya adalah kegiatan yang menyita waktu. Bekerja akan mempunyai pengaruh terhadap kehidupan keluarga. Adapun salah satu faktor yang mempengaruhi peran seseorang diantaranya adalah pekerjaan. Seseorang yang bekerja secara umum akan mendapatkan pendapatan, sehingga segala aspek yang dibutuhkan terutama dalam menunjang pencegahan maupun pengobatan keluarga akan terpenuhi. Hal ini sesuai dengan Notoatmodjo (2012), pekerjaan merupakan hal untuk memperoleh pendapatan yang cukup untuk dapat mendukung untuk meningkatkan kesadaran seseorang tentang kesehatan khususnya kesehatan gigi dan mulut.

Menurut peneliti pekerjaan orang tua dapat mempengaruhi komunikasi dan perhatian orang tua terhadap anak. Orang tua yang bekerja dalam waktu yang lama tidak memiliki waktu untuk mendidik dan mengawasi anaknya dalam merawat gigi. Keterbatasan waktu untuk bertemu dengan anak membuat komunikasi dan perhatian orang tua terhadap kesehatan anak terabaikan. Orang tua atau ibu yang tidak bekerja akan lebih sering dirumah dan memiliki waktu untuk membimbing atau mengajarkan anaknya bagaimana cara menjaga kesehatan gigi yang baik dan benar daripada ibu yang memiliki pekerjaan diluar rumah. Orang tua yang bekerja sebagai ibu rumah tangga mempunyai banyak waktu dengan anaknya sehingga ibu dengan leluasa dapat mengajarkan anaknya bagaimana cara menyikat gigi yang benar dan dapat mengawasi makanan apa saja yang dikonsumsi anaknya.

\section{Teknik Menggosok Gigi yang Baik dan Benar pada Anak Prasekolah di PAUD Dewi Sartika Kelurahan Dinoyo Kecamatan Lowokwaru Kota Malang}

Berdasarkan tabel 5.6 frekuensi terhadap teknik menggosok gigi anak usia prasekolah dari 42 responden terdapat hampir setengahnya tergolong dalam 
kategori teknik menggosok gigi yang baik yaitu 42,85\%, hampir setengahnya tergolong dalam kategori teknik menggosok gigi yang cukup yaitu 38,09\% dan sebagian kecil tergolong dalam ketegori teknik menggosok gigi yang kurang yaitu 19,04\%. Menyikat gigi adalah suatu tindakan yang sangat penting dilakukan mulai dari anak - anak sampai orang dewasa untuk menjaga agar kesehatan gigi dan mulutnya tetap dalam keadaan baik. Pada dasarnya menyikat gigi yang baik adalah menyikat semua permukaan gigi sampai bersih dan plak juga hilang sempurna dengan gerakan menyikat gigi yang pendek dan tidak terburu - buru (Machfoedz, dkk., 2006).

Menurut (Hamidi, 2006) cara atau teknik menggosok gigi yang baik adalah membersihkan seluruh bagian gigi gerakan vertikal, dan bergerak lembut. Seluruh permukaan gigi dalam, luar, dan pengunyah harus disikat dengan teliti. Gigi digosok dengan ujung bulu sikat diletakkan dengan kuat pada sudut 45 derajat pada gigi dan gusi digerakkan ke depan dan belakang dengan gerakan memutar, bergerak dengan lembut. Dari hasil observasi yang dilakukan peneliti teknik menggosok gigi yang baik dan benar pada anak prasekolah di Paud Dewi Sartika teknik menggosok gigi yang paling sering digunakan oleh anak adalah teknik menggosok permukaan gigi atas dan bawah, terdapat beberapa anak yang melakukan teknik menggosok gigi yang kurang baik dan benar yang berjumlah 5 anak yaitu anak tersebut hanya menggosok gigi bagian depan dan ada yang menggosok gigi Cuma menggunakan teknik vertical dan horizontal.

Berdasarkan hasil penelitian di atas siswa yang melakukan teknik menggosok gigi yang kurang benar sebanyak 19,04\%.
Hal ini dilihat dari observasi peneliti sebagian besar anak yang berusia 4 tahun yang masih kurang memahami bagaimana teknik menggosok gigi yang baik dan benar. Hal ini disebabkan karena usia anak yang masih 4 tahun dimana anak belum memahami dengan benar pentingnya menjaga kesehatan gigi dan dimana seharusnya anak yang berusia 4 tahun lebih sering diajarkan dan dibiasakan untuk menggosok gigi, sedangkan dari hasil kuesioner yang peneliti dapatkan 11 orangtua yang tidak pernah mengajarkan anak untuk menggosok gigi dengan gerakan memutar (bulat-bulat) dan ada 12 orangtua yang tidak pernah mengajarkan anaknya untuk menggosok lidah.

Dilihat dari hasil observasi yang dilakukan peneliti anak perempuan lebih patuh dan rajin untuk meyikat gigi dibandingkan anak laki-laki. Berdasarkan tabel 5.2 dapat diketahui bahwa jenis kelamin responden sebagian besar adalah perempuan yaitu 26 orang $(61,9 \%)$ sedangkan sisanya adalah laki-laki yaitu 16 orang $(38,1 \%)$.

Menurut Wong (2009), rata-rata anak laki-laki memulai dan menguasai menyikat gigi lebih lama dibandingkan anak perempuan karena sistem syaraf anak lakilaki berkembang lebih lama sehingga anak laki-laki jarang memperhatikan sesama lakilaki yang menjadi figur panutannya. Anak laki-laki juga kurang sensitif dengan rasa basah di kulit mereka.

Perilaku ini diduga dipengaruhi oleh perbedaan psikologis anak. Anak laki-laki diduga cenderung lebih tidak memperhatikan keadaan diri mereka sendiri termasuk kesehatan gigi dan mulut. Hal ini diduga adanya perbedaan kondisi gen dari 
anak perempuan dan laki-laki ( Mirani, 2009 ).

Menurut peneliti teknik menggosok gigi yg baik lebih cepat dikuasai oleh anak perempuan karena anak perempuan lebih menurut jika dibimbing dan diajarkan cara menggosok gigi yang baik sedangkan anak laki-laki kadang cenderung sering menolak jika dibimbing dan diajarkan cara menggosok gigi yang baik sama orang tua mereka.

\section{Hubungan antara peran orangtua dengan teknik menggosok gigi yang baik dan benar pada anak usia prasekolah di di PAUD Dewi Sartika Kelurahan Dinoyo Kecamatan Lowokwaru Kota Malang}

Dari hasil penelitian yang dilakukan oleh peneliti pada bulan juli sampai agustus 2018 dengan jumlah responden 42 orang di PAUD Dewi Sartika Kelurahan Dinoyo Kecamatan Lowokwaru Kota Malang dengan menggunakan uji spearman sebesar $(r)=0,628$. Nilai signifikansi sebesar 0,000. nilai sig $\alpha<0,05$ Nilai signifikansi lebih kecil dari $\alpha=0,05$, menunjukkan adanya hubungan antara peran orang tua dengan teknik menggosok gigi yang baik dan benar pada anak usia prasekolah yaitu kuat.

Menurut Riyanti (2009) mengatakan bahwa peran orang sangat diperlukan dalam membimbing, memberikan pengertian, mengingatkan dan menyediakan fasilitas kepada anak agar anak dapat memelihara kebersihan giginya. Selain itu orang tua juga mempunyai peran yang cukup besar dalam mencegah terjadinya peningkatan plak pada gigi dan terjadinya karies pada anak. Pengetahuan orang tua sangat penting dalam mendasari terbentuknya perilaku yang mendukung atau tidak mendukung kebersihan gigi anak. Pengetahuan tersebut dapat diperoleh secara alami maupun secara terencana yaitu melalui proses pendidikan. Orang tua dengan pengetahuan rendah mengenai kesehatan gigi merupakan faktor predisposisi dari perilaku yang tidak mendukung kesehatan gigi anak. Berdasarkan tabel 5.7 hubungan antara peran orangtua dengan teknik menggosok gigi yang baik dan benar pada anak pra sekolah didapatkan hasil bahwa diketahui dari 21 responden yang mempunyai peran orangtua yang baik maka sebagian besar teknik menggosok gigi anak baik yaitu $(66,7 \%)$, dari 12 responden yang mempunyai peran orangtua yang cukup didapatkan hasil hampir setengahnya teknik menggosok gigi anak cukup yaitu $(41,7 \%)$ dan dari 9 responden yang mempunyai peran orangtua yang kurang didapatkan hasil sebagian besar teknik menggosok gigi anak kurang yaitu $(55,6 \%)$.

Menurut peneliti orangtua yang mendampingi dan mendidik anaknya untuk merawat gigi secara tidak langsung orangtua membiasakan anaknya untuk rajin menjaga dan merawat giginya. Selain itu orangtua yang jarang mengajarkan anaknya menggosok gigi dan hanya mengingatkan saja tanpa diawasi akan membuat anaknya malas dalam menggosok gigi karena tidak ada orangtua yang mengawasinya. Maka, dari hasil penelitian ini dapat disimpulkan bahwa orangtua yang selalu membimbing, mengingatkan dan mengawasi anaknya dalam menggosok gigi maka anaknya akan rajin menggosok gigi dan teknik menggosok giginya juga benar.

\section{KESIMPULAN}

Berdasarkan hasil penelitian yang dilakukan di PAUD Dewi Sartika Kelurahan Dinoyo Kecamatan Lowokwaru 
PROFESIONAL HEALTH JOURNAL

Volume2, No. 2, Juni 2021 (Hal. 90-100)

https://www.ojsstikesbanyuwangi.com/index.php/PHJ

Kota Malang dan berdasarkan tujuan penelitian yang telah dibahas sebelumnya maka dapat disimpulkan sebagai berikut :

1. Peran orang tua pada anak usia prasekolah di PAUD Dewi Sartika Kelurahan Dinoyo Kecamatan Lowokwaru Kota Malang setengah dari responden termasuk dalam kategori peran orangtua yang baik yaitu 21 responden $(50 \%)$.

2. Teknik menggosok gigi yang baik dan benar pada anak prasekolah di PAUD Dewi Sartika Kelurahan Dinoyo Kecamatan Lowokwaru Kota Malang hamper dari setengahnya termasuk dalam kategori teknik menggosok gigi yang baik yaitu 18 responden $(42,85 \%)$.

3. Ada hubungan antara peran orangtua dengan teknik menggosok gigi yang baik dan benar pada anak usia prasekolah di PAUD Dewi Sartika Kelurahan Dinoyo Kecamatan Lowokwaru Kota Malang

\section{DAFTAR RUJUKAN}

Amin, M. AL, Hariyanto, P., Efendi, A., \& Yanuar, A. (2018). TRIAS UKS TERHADAP UPAYA PENCEGAHAN KENAKALAN REMAJA PADA SISWATINGKAT SMA / MA

Muhammad Al Amin, dkk. Efektifitas

Pembinaan Kader Kesehatan PENDAHULUAN UKS merupakan usaha memberikan umur 16-19 th sebanyak 8 orang , 20-24 th pendidikan tetntang kesehat. 1(1), 27 38.

https://www.ojsstikesbanyuwangi.com /index.php/PHJ/article/view/95/81

Anitasari S, Liliwati, (2010). Pengaruh Frekuensi Menyikat Gigi Terhadap Tingkat Kebersihan Gigi dan Mulut. Dentika Dent J.
Arikunto, S. (2010). Prosedur penelitian : Suatu Pendekatan Praktik. (Edisi Revisi). Jakarta : Rineka Cipta

Ariningrum, R. (2007). Beberapa cara menjaga kebersihan gigi dan mulut. Cermin Dunia Kedokteran

BKKBN, (2011). Peran Orangtua dalam Membina Balita, Anak dan Remaja. Jakarta

Brooks, J, (2011). The procees of parenting (rahmad fajar, penerjemah). Edisi kedelapan. Yogyakarta: pustaka pelajar

Budiman \& Riyanto A. (2013). Kapita Selekta Kuisioner Pengetahuan Dan Sikap Dalam Penelitian Kesehatan. Jakarta : Salemba Medika

Fitria, Nita. (2013). Laporan Pendahuluan Tentang Masalah Psikososial. Jakarta : Salemba Medika.

Ginandjar R, (2011). Cara Menyikat Gigi Yang Benar. www.pikiran-rakyat.com

Gultom, M, (2009). Pengetahuan, sikap dan tindakan ibu-ibu rumah tangga terhadap pemeliharaan kesehatan gigi dan mulut anak balitanya, Di Kecamatan Balige, Kabupaten Toba Samosir, Sumatera Utara.

Hidayat, A A. (2008). Pengantar Ilmu Keperawatan Anak 1. Jakarta: Salemba Medika

Machfoedz, ircham.(2006). Menjaga kesehatan gigi dan mulut anak-anak dan ibu hamil. Yogyakarta : fitramaya

Maulani, chaerita (2005). Kiat merawat gigi anak ; panduan orang tua dalam 


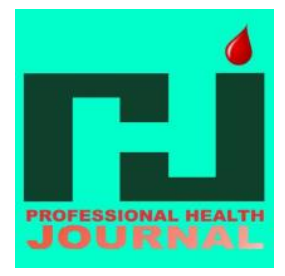

merawat dan menjaga kesehatan gigi bagi anak-anaknya. Jakarta : PT elex media kumputindo

Mubarak, dkk., (2009). Ilmu Keperawatan Komunitas Konsep Dan Aplikasi. Jakarta : Salemba Medika

Muttaqin, arief dkk.(2010) Gangguan gastrointestinal. Banjarmasin.

Notoatmodjo, Soekidjo. (2012). Metodologi Penelitian Kesehatan. Jakarta: Rineka Cipta.

Notoatmodjo, Soekidjo. (2007). Pendidikan dan Perilaku Kesehatan. Jakarta: Rineka Cipta

Notoadmojo, Soekidjo. (2007). Promosi Kesehatan dan Perilaku. Jakarta: Rineka Cipta

Nursalam, Dkk. (2007). Asuhan Keperawatan Bayi dan Anak. Jakarta: Salemba Medika

Nursalam, (2011) Manajemen Keperawatan : Aplikasi dalam Praktik Keperawatan Profesional.Jakarta.Salemba Medika

Nursalam. (2013). Metodologi Penelitian Kesehatan. Jakarta: Salemba Medika.

Padmenodewo S. (2008). Pendidikan Anak

Pra Sekolah. Jakarta : rineka cipta

Papalia, dkk., (2008). Human development, perkembangan manusia. Jakarta : Salemba Humanika

Pintauli S, Hamada T., (2008). Menuju Gigi dan Mulut Sehat, Pencegahan dan Pemeliharaan. Medan : USU Press.

Pratiwi D. (2009). Gigi Sehat Dan Cantik. PT Kompas Media Nusantara. Jakarta.
PROFESIONAL HEALTH JOURNAL

Volume2, No. 2, Juni 2021 (Hal. 90-100)

https://www.ojsstikesbanyuwangi.com/index.php/PHJ

Ramadhan, A.G (2010). Serba Serbi Kesehatan Gigi Dan Mulut. Jakarta; Bukune.

Riskesdas. 2013. Riset Kesehatan Dasar Tahun (2013). Kementrian Kesehatan Republik Indonesia: Jakarta.

Riyadi, Sujono \& Sukarmin. (2009). Asuhan Keperawatan Pada Anak, edisi 1, Yogyakarta : Graha Ilmu.

Riyanti, E., dan Saptarini, R., (2009). Upaya Peningkatan Kesehatan Gigi dan Mulut Melalui Perubahan Perilaku Anak, MIKGI,

Soekidjo Notoatmojo. (2010). Kesehatan Masyarakat: ilmu dan seni. Jakarta : Rineka Cipta.

Soetjiningsih. (2012). Perkembangan Anak dan Permasalahannya dalam Buku Ajar I IlmuPerkembangan Anak Dan Remaja. Jakarta :Sagungseto

Solikin, Muhlisin HM, Kartinah A, (2013). Hubungan tingkat pengetahuan orang tua tentang kesehatan gigi dan mulut dengan kejadian karies gigi pada anak prasekolah di TK 01 Pertiwi Karangbangun Karanganyar. Surakarta: Program Studi Ilmu Keperawatan Fakultas Ilmu Kesehatan Universitas Muhammadiyah

Suciari, A. dkk (2015). Peran Orang Tua Dalam Membimbing Menyikat Gigi Dengan Kejadian Karies Gigi Anak Prasekolah. http//journal.unair.ac.id (diakses 15 januari 207) 
Sugiyono. (2012). Metode Penelitian Kuantitatif, Kualitatif, dan $R$ \& $D$. Bandung : Alfabeta

Suherman, (2010) . Perkembangan Anak . Jakarta : EGC

Supartini, Yupi. (2008). Buku Ajar Konsep Dasar Keperawatan Anak. Jakarta: EGC

Suryawati,S.dkk (2009). Prevalensi Nursing Mouth Caries pada anak usia 15 - 60 bulan berdasarkan frekuensi penyikatan gigi. http//resources.unpad.ac.id ( diakses tgl 15 januari 2017 ).

Susi, Bachtiar H, Azmi U, (2012). Hubungan Status Sosial Ekonomi Orang Tua Dengan Karies Gigi Sulung Pada Anak Umur 4 Dan 5 Tahun. Majalah Kedokteran Andalas.

Whaley, \& Wong. (2009).Buku Ajar Klinis Keperawatan Pediatrik Edisi 6. Jakarta : EGC

Wong, Donna L. (2008). Buku Ajar Keperawatan Pediatrik Wong. Jakarta: EGC

World Health Organization (WHO). (2012). Oral Health. Di akses 20 februari 2017 , darihttp://www.who.int/mediacentre/ factsheets/fs318/en/ 